\title{
A Novel Thermal Curing Reaction of Oxetane Resin with Active Diester
}

\author{
By Tadatomi NISHIKUBO, ${ }^{*}$ Hiroto KUDO, and Hiroshi NOMURA
}

\begin{abstract}
Thermal curing reactions of oxetane resins \{mixtures of novolac type oxetane (PNOX) with 2,2'-bis $\{(3-$-ethyl-3oxetanyl)methoxy $\}$ biphenyl (2,2'-BPOX) and mixtures of tris $\{4-[(3-e t h y l-3$-oxetanyl)methoxy]phenyl $\}$ methane (THPMOX) with 2,2'-BPOX with active diester, 4,4'-isopropylidenebis(2,6-dichlorophenyl diacetate) (IBDCPA) were examined using certain quaternary phosphonium salts as catalysts. The thermal curing reaction of oxetane resins with IBDCPA proceeded smoothly at $170-190^{\circ} \mathrm{C}$ to produce insoluble gel products. However, the rate of gel production was strongly affected by catalyst concentration and reaction temperature, and gel products were obtained in the highest yield when the reaction was carried out at $190{ }^{\circ} \mathrm{C}$ in bulk using $7 \mathrm{~mol} \%$ of tetraphenylphosphonium chloride (TPPC) as a catalyst. The glass transition temperatures $\left(T_{\mathrm{g}}\right) \mathrm{s}$ and 5 weight- $\%$ of loss temperatures $\left(T_{\mathrm{d}}{ }^{5 \%}\right) \mathrm{s}$ of the resulting gel products were determined by DSC and TGA analysis, and it was found that their $T_{\mathrm{g}} \mathrm{s}$ and $T_{\mathrm{d}}{ }^{5 \%} \mathrm{~s}$ were $97-118^{\circ} \mathrm{C}$ and $374-380^{\circ} \mathrm{C}$, respectively, when the thermal curing reaction of oxetane resins PNOX $/ 2,2^{\prime}$-BPOX with equivalent amount of cross-linker IBDCPA was performed using TPPC as a catalyst in bulk. On the other hand, the $T_{\mathrm{g}} \mathrm{S}$ and $T_{\mathrm{d}}{ }^{5 \%} \mathrm{~s}$ of gel products obtained from the reaction of oxetane resins THPMOX/2,2'-BPOX with IBDCPA using the same catalyst were $96-128{ }^{\circ} \mathrm{C}$ and $381-386{ }^{\circ} \mathrm{C}$, respectively.

KEY WORDS: Oxetane Resin / Polyfunctional Oxetane / Bis(oxetane) / Cross-linking Reagent / Active Bis(ester) / Gel Product /
\end{abstract}

It is well known ${ }^{1}$ that thermal curing reactions of epoxy resins with certain cross-linkers such as polyfunctional-amines, -phenols, -thiols, and -carboxylic acids proceed smoothly using appropriate catalysts. In these reaction systems, the cured epoxy resins produced pendant hydroxyl groups. It is thought that the produced pendant hydroxyl groups in the cured resins increased its glass transition temperature $\left(T_{\mathrm{g}}\right)$ and bondstrength between the resin and the surface of the substrate. Therefore, the thermal curing reactions of epoxy resins with the above cross-linkers have been widely used in many industries as coatings, paintings, elastomers, adhesions, and electronics. However, it has been pointed out recently that the generation of the hydroxyl groups in the cured resins strongly decreased electric insulation property of the epoxy resins after moisture exposure.

About 15 years ago, we have successfully found ${ }^{2}$ new addition reactions of oxiranes with active ester, active aryl ether, silyl ether, and phosphonyl ester. We also examined ${ }^{3}$ their application to develop new epoxy resins with high performance and excellent functionality based on new organic reactions of the oxiranes. Then, we found that the cured epoxy resins using polyfunctional active esters can be achieved excellent electric insulating property. Therefore, these thermal curing systems have great possibilities to be used in industry, especially in electronic industry.

On the other hand, 4-membered cyclic ethers, oxetanes have mostly same strain energy ${ }^{4}(107 \mathrm{~kJ} / \mathrm{mol})$ as 3 -membered cyclic ethers, oxiranes. Accordingly, the same chemical reactivity of oxetanes has been anticipated for long time. However, it has not been reported any useful organic reactions of oxetane compounds excepting general cationic ring-opening polymerizations ${ }^{5}$ and cationic-isomerizations of oxetane derivatives, which have been reported very recently by Motoi ${ }^{6}$ and his-coworkers.

From these scientific backgrounds, the authors examined to develop new organic reactions of oxetane compounds, and succeeded to develop certain new addition reactions of oxetane compounds with acyl chloride, ${ }^{7}$ silyl chloride, ${ }^{8}$ phosphonyl chloride, ${ }^{9}$ phenol, ${ }^{10}$ thiol, ${ }^{11}$ carboxylic acid, ${ }^{12}$ and active ester ${ }^{13}$ using certain quaternary onium salts as catalysts, a novel anionic ring-opening polymerization 2-hydroxymethyl oxetanes ${ }^{14}$ using potassium tert-butoxide/18-crown-6 as a catalyst, and an anionic ring-opening alternating copolymerization of oxetane with carboxylic anhydride ${ }^{15}$ using quaternary onium salts as catalysts. All these reactions proceeded smoothly under suitable reaction conditions to give the corresponding adducts and polymers in satisfactory yields.

More recently, we also found ${ }^{16}$ that the polyaddition of bis(oxetane)s with active bis(ester)s proceeded smoothly at 160- $180^{\circ} \mathrm{C}$ using the same catalyst system, affording corresponding poly(ether)s with pendant ester groups. This means that there is a great possibility to develop a new thermal curing system of oxetane resin. In this article, the authors examined to develop a novel thermal curing reaction of oxetane resins \{mixtures of novolac type oxetane (PNOX) with 2,2'bis $\left\{(3\right.$-ethyl-3-oxetanyl)methoxy $\}$ biphenyl $\left(2,2^{\prime}\right.$-BPOX) and mixtures of $\{4-[(3-e t h y l-3-o x e t a n y l) m e t h o x y]$ phenyl $\}$ methane (THPMOX) with 2,2'-BPOX $\}$ with active diester, 4,4'-isopropylidenebis(2,6-dichlorophenyl diacetate) (IBDCPA).

Department of Applied Chemistry, Faculty of Engineering, Kanagawa University, Rokkakubashi, Kanagawa-ku, Yokohama 221-8686, Japan

*To whom correspondence should be addressed (E-mail: nishikubot@ kanagawa-u.ac.jp). 


\section{EXPERIMENTAL}

\section{Materials}

Reagent grade tetraphenylphosphonium bromide (TPPB), tetraphenylphosphonium chloride (TPPC), and tetraphenylphosphonium iodide (TPPI) were dried in vacuo, and used without further purification. All oxetane compounds, 2,2'BPOX, THPMOX, and PNOX, which were donated from Toagosei Co. Ltd., were used without further purification. IBDCPA (mp. $140^{\circ} \mathrm{C}$ ) was synthesized in $73 \%$ yield by the reaction of 2,2',6,6'-tetrachlorobisphenol-A with acetyl chloride according the reported ${ }^{16}$ methods.

\section{Measurement}

Infrared (IR) absorption spectra were measured on a Jasco model FT/IR-420 spectrometer. Glass transition temperatures $\left(T_{\mathrm{g}}\right) \mathrm{s}$ of mixtures of oxetane resins and the mixtures of oxetane resins with cross-linker IBDCPA were performed by reverse heat flow method using a TA Instruments model DSC Q100 differential scanning calorimeter (DSC) at a heating cycle of $1{ }^{\circ} \mathrm{C} / \mathrm{min}$ and at a heating rate of $3{ }^{\circ} \mathrm{C} / \mathrm{min}$ from $-70^{\circ} \mathrm{C}$ to $330^{\circ} \mathrm{C}$ under nitrogen atmosphere. Initial reaction temperatures, maxima reaction temperatures, and reaction heats were also measured under the same conditions. $T_{\mathrm{g}} \mathrm{s}$ of the cured oxetane resins were measured on a Seiko Electronic Instruments model EXSTAR 6000/ DSC6200 differential scanning calorimeter (DSC) at a heating rate of $10^{\circ} \mathrm{C} / \mathrm{min}$ under nitrogen atmosphere. Thermal analysis (TGA) of the cured oxetane resins was performed on a Seiko Electronic Instruments model EXSTAR 6000/TG/DTA 6220 at a heating rate of $10^{\circ} \mathrm{C} /$ min under nitrogen.

\section{Measurement of $\boldsymbol{T}_{\mathrm{g}} \mathrm{s}$ of Mixtures of PNOX with 2,2'-BPOX}

PNOX or THPMOX with $2,2^{\prime}$-BPOX were charged into $5 \mathrm{~mL}$ of the glass sample tube with appropriate weight ratios $(w t / w t=10 / 0,9 / 1,8: 3,7 / 3,6 / 4$, and 5/5) and these oxetane compounds were mixed uniformly at $140{ }^{\circ} \mathrm{C}$ for $60 \mathrm{~min}$ by stirring. Each sample (3-4 mg) was packed in an aluminum sample tube for DSC analysis, and the sample was heated at $3{ }^{\circ} \mathrm{C} / \mathrm{min}$ under nitrogen. $T_{\mathrm{g}} \mathrm{s}$ of mixtures of oxetane resins with equivalent amount of a cross-linker IBDCPA and a catalyst TPPC ( $7 \mathrm{~mol} \%$ to oxetane group) were also measured by the same procedure.

\section{Typical Example of the Measurement of Thermal Curing Reaction of Oxetane Resin with IBDCPA by DSC}

The mixture of PNOX (0.400 g, $1.98 \mathrm{mmol}$ as oxetane), 2,2'BPOX $(0.100 \mathrm{~g}, 0.52 \mathrm{mmol}$ as oxetane), IBDCPA $(0.564 \mathrm{~g}$, $2.5 \mathrm{mmol}$ as ester), and TPPC (66 $\mathrm{mg}, 0.176 \mathrm{mmol} ; 7 \mathrm{~mol} \%$ to oxetane group) were charged into $5 \mathrm{~mL}$ of the glass sample tube and mixed uniformly at $150{ }^{\circ} \mathrm{C}$ for $90 \mathrm{~min}$ by stirring. The mixture (3-4 mg) was packed in an aluminum sample tube for DSC analysis, and the sample was heated at $3{ }^{\circ} \mathrm{C} / \mathrm{min}$ under nitrogen.

\section{Measurement of Gel Production by the Reaction of Oxetane Resin with IBDCPA}

Typical procedure was as follows: PNOX $(0.400 \mathrm{~g}, 1.98$ mmol), 2,2'-BPOX (0.100 g, $0.52 \mathrm{mmol})$, IBDCPA $(0.564 \mathrm{~g}$, $2.5 \mathrm{mmol}$ ), and TPPC (66 mg, $0.176 \mathrm{mmol} ; 7 \mathrm{~mol} \%$ to oxetane group) were taken into $5 \mathrm{~mL}$ of the glass sample tube, and the oxetane resins, the cross-linker, and the catalyst were mixed uniformly at $150{ }^{\circ} \mathrm{C}$ for $90 \mathrm{~min}$ by stirring. The mixture in the glass tube was heated at $170-190^{\circ} \mathrm{C}$ for appropriate time. THF was added into the sample tube, and the mixtures were stirred at room temperature for $24 \mathrm{~h}$ to dissolve un-reacted starting materials, and then, the insoluble gel products were separated by a centrifugation. The obtained insoluble gel products were suspended three times to remove the catalyst, filtered, and dried at $60^{\circ} \mathrm{C}$ for $24 \mathrm{~h}$ in vacuo.

\section{Measurement of Addition Reaction of Oxetane Resin with Difunctional Phenol (IBDCPA)}

The sample prepared from PNOX $(0.400 \mathrm{~g}, 1.98 \mathrm{mmol}$ as oxetane), 2,2'-BPOX (0.100 g, $0.52 \mathrm{mmol}$ as oxetane), IBDCPA $(0.564 \mathrm{~g}, 2.5 \mathrm{mmol}$ as ester), and TPPC (66 mg, $0.176 \mathrm{mmol} ; 7 \mathrm{~mol} \%$ to oxetane group) as the above method was dissolved in bulk, and the solution was coated on $\mathrm{KBr}$ plate to make thin film, and then the dried thin film on the $\mathrm{KBr}$ plate was heated in the chamber at appropriate temperature. The decrease of the absorption peak at $983 \mathrm{~cm}^{-1}$ due to the oxetane groups were measured by FT/IR spectrometry.

\section{Thermal Analysis of the Cured Oxetane Resin}

The cured resin sample (about $7 \mathrm{mg}$ ) was packed in an aluminum sample tube for DSC analysis, and the sample was heated at $10^{\circ} \mathrm{C} / \mathrm{min}$ under nitrogen until $250^{\circ} \mathrm{C}$ to conform $T_{\mathrm{g}}$. TGA analysis was also performed by the same way until $600{ }^{\circ} \mathrm{C}$, and initial weight loss temperatures $\left(T_{\mathrm{d}}{ }^{\mathrm{i}}\right) \mathrm{s}$ of the cured resin were measured.

\section{RESULTS AND DISCUSSION}

As described in the introduction, the authors reported ${ }^{16}$ successful synthesis of poly(ether)s by the polyaddition of bis(oxetane)s with certain active bis(ester)s using quaternary onium salts or crown ether complexes as catalysts in DMAc and NMP. Although this reaction did not occur at lower temperatures than $110^{\circ} \mathrm{C}$ even in the presence of appropriate catalyst, the reaction proceeded smoothly at higher temperatures than $140^{\circ} \mathrm{C}$. That is, this polyaddition reaction has a great possibility as new thermo-setting system with hydrophobic property.

To develop a new thermo-setting system based on oxetane resin as the same of epoxy resin, we prepared certain mixtures of polyfunctional oxetanes (oxetane resins) such as PNOX and THPMOX with $2,2^{\prime}$-BPOX and measured $T_{\mathrm{g}} \mathrm{s}$ of the mixtures of oxetane resins. Oxetane resin, PNOX with $T_{\mathrm{g}}$ at $27^{\circ} \mathrm{C}$ is solid material at room temperature, and commercial $2,2^{\prime}$-BPOX with $T_{\mathrm{g}}$ at $-28^{\circ} \mathrm{C}$ is liquid material with low viscosity at room temperature. As shown in Figure 1, $T_{\mathrm{g}} \mathrm{s}$ of homogeneous 

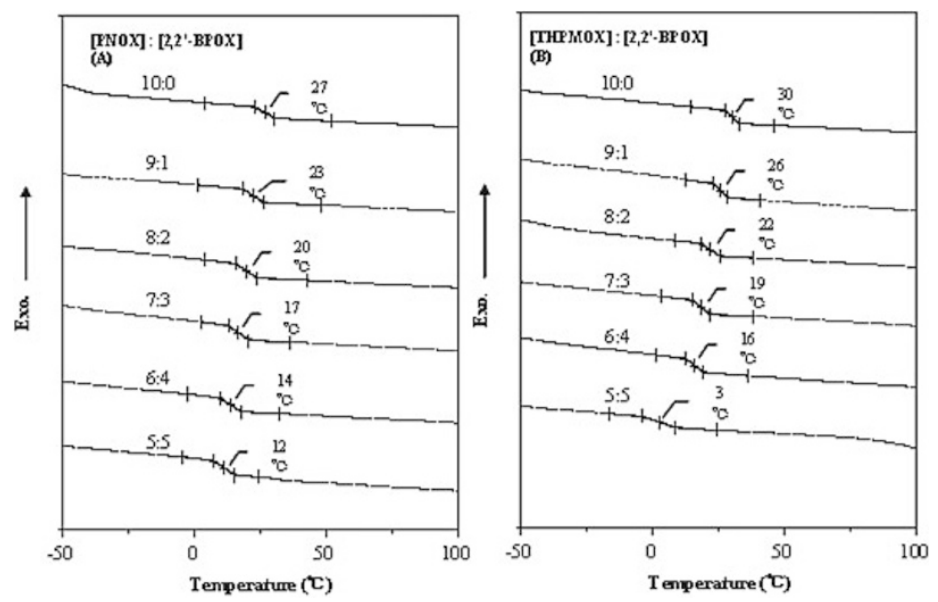

Figure 1. $T_{g} s$ of the mixtures of PNOX/2,2'-BPOX (A) and THPMOX/2,2'-BPOX (B).

mixtures of oxetane resins gradually fell with increasing the added 2,2'-BPOX, and $T_{\mathrm{g}} \mathrm{s}$ of the mixture of $\operatorname{PNOX}(9) / 2,2^{\prime}-$ $\operatorname{BPOX}(1), \operatorname{PNOX}(8) / 2,2^{\prime}-\operatorname{BPOX}(2), \operatorname{PNOX}(7) / 2,2^{\prime}-\operatorname{BPOX}(3)$, $\operatorname{PNOX}(6) / 2,2^{\prime}-\mathrm{BPOX}(4)$, and $\operatorname{PNOX}(5) / 2,2^{\prime}-\mathrm{BPOX}(5)$ were $23,20,17,14$, and $12^{\circ} \mathrm{C}$, respectively (Figure $1(\mathrm{~A})$ ). We also examined the $T_{\mathrm{g}}$ values of certain mixtures consisting of THPMOX(10)/2,2'-BPOX(0), THPMOX(9)/2,2'-BPOX(1),

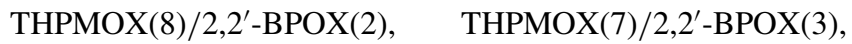
THPMOX(6)/2,2'-BPOX(4), and THPMOX(5)/2,2'-BPOX(5), respectively, and it was observed that these values gradually fell increasing the ratio of 2,2'-BPOX (Figure 1(B)).

$T_{\mathrm{g}} \mathrm{s}$ of mixtures of equivalent amount of oxetane resins with cross-linker, IBDCPA and $7 \mathrm{~mol} \%$ of catalyst, TPPC were examined (Table I). The $T_{\mathrm{g}} \mathrm{s}$ of the mixture of $\mathrm{PNOX}(10) / 2,2^{\prime}$ $\operatorname{BPOX}(0)$ with IBDCPA/TPPC, PNOX(9)/2,2'-BPOX(1) with IBDCPA/TPPC, PNOX(8)/2,2'-BPOX(2) with IBDCPA/ TPPC, $\operatorname{PNOX}(7) / 2,2^{\prime}-\mathrm{BPOX}(3)$ with IBDCPA/TPPC, PNOX(6)/2,2'-BPOX(4) with IBDCPA/TPPC, and PNOX(5)/ 2,2'-BPOX(5) with IBDCPA/TPPC were 29, 24, 21, 19, 15,

Table I. $T_{\mathrm{g}} \mathrm{s}$ of mixtures of oxetane resins ${ }^{\mathrm{a})}$

\begin{tabular}{|c|c|c|}
\hline Ratio of oxetanes (wt/wt) & $\begin{array}{c}T_{\mathrm{g}} \text { of oxetane } \\
\text { resins without } \\
\text { IBDCPA and TPPC } \\
\end{array}$ & $\begin{array}{c}T_{\mathrm{g}} \text { of oxetane } \\
\text { resins with } \\
\text { IBDCPA and TPPC }\end{array}$ \\
\hline & $\left({ }^{\circ} \mathrm{C}\right)$ & $\left({ }^{\circ} \mathrm{C}\right)$ \\
\hline PNOX(10)/2,2'-BPOX(0) & 27 & 29 \\
\hline PNOX(9)/2,2' -BPOX(1) & 23 & 24 \\
\hline PNOX(8)/2,2' -BPOX(2) & 20 & 21 \\
\hline PNOX(7)/2,2' -BPOX(3) & 17 & 19 \\
\hline PNOX(6)/2,2'-BPOX(4) & 14 & 15 \\
\hline PNOX(5)/2,2'-BPOX(5) & 12 & 14 \\
\hline THPMOX(10)/2,2'-BPOX(0) & 30 & 30 \\
\hline THPMOX(9)/2,2'-BPOX(1) & 26 & 26 \\
\hline THPMOX(8)/2,2'-BPOX(2) & 22 & 23 \\
\hline THPMOX(7)/2,2'-BPOX(3) & 19 & 19 \\
\hline THPMOX(6)/2,2'-BPOX(4) & 16 & 16 \\
\hline THPMOX(5)/2,2'-BPOX(5) & 3 & 14 \\
\hline
\end{tabular}

a) Glass transition temperatures $\left(T_{\mathrm{g}}\right) \mathrm{s}$ of mixture of oxetane resins and the mixtures of oxetane resins with cross-linker IBDCPA were performed on a TA Instruments model DSC Q100 differential scanning calorimeter (DSC) at a heating rate of $3^{\circ} \mathrm{C} / \mathrm{min}$ under nitrogen atmosphere. and $14{ }^{\circ} \mathrm{C}$, respectively. This means that the $T_{\mathrm{g}} \mathrm{s}$ of the mixtures of PNOX with $2,2^{\prime}$-BPOX slightly rose by the addition of IBDCPA and TPPC. This data also suggested that homogenious mixtures were prepared by mixing of PNOX, 2,2'-BPOX, IBDCPA, and TPPC under appropriate temperatures, and each mixture showed one $T_{\mathrm{g}}$.

The $T_{\mathrm{g}} \mathrm{s}$ of the mixtures of THPMOX(10)/2,2'-BPOX(0) with IBDCPA/TPPC, THPMOX(9)/2,2'-BPOX(1) with IBDCPA/TPPC, THPMOX(8)/2,2'-BPOX(2) with IBDCPA/ TPPC, THPMOX(7)/2,2'-BPOX(3) with IBDCPA/TPPC, THPMOX(6)/2,2'-BPOX(4) with IBDCPA/TPPC, and THPMOX(5)/2,2'-BPOX(5) with IBDCPA/TPPC were 30 , 26, 23, 19, 16, and $14{ }^{\circ} \mathrm{C}$, respectively. This means that homogenious mixtures were also prepared by mixing of THPMOX, 2,2'-BPOX, IBDCPA, and TPPC under appropriate temperatures, and the same tendency concerning the values of $T_{\mathrm{g}} \mathrm{s}$ in the case of the mixtures of THPMOX was observed in the case of PNOX.

Then, we examined the thermal-curing reaction of oxetane resins with cross-linker; IBDCPA using TPPC as a catalyst by DSC measurement. As shown in Figure 2, the progress of the reactions of the mixtures of PNOX, 2.2'-BPOX, and IBDCPA were confirmed at $184-189^{\circ} \mathrm{C}$ as initial reaction temperatures, and as maximal reaction temperatures at $232-242^{\circ} \mathrm{C}$, respectively. We also calculated calorific values (164-208 J/g) based on the addition reaction of oxetane resin, PNOX-2,'-BPOX with cross-linker, IBDCPA (Figure 2(A)).

The reactions of the same mixtures of THPMOX, 2,2'-BPOX, and IBDCPA also proceeded catalyzed by TPPC, and the initial reaction temperatures and maximal reaction temperatures were confirmed at $188-191{ }^{\circ} \mathrm{C}$ and at $232-237^{\circ} \mathrm{C}$, respectively. We also conformed similar calorific values $(188-199 \mathrm{~J} / \mathrm{g})$ from the addition reaction of oxetane resins, THPMOX $/ 2,2^{\prime}$-BPOX with cross-linker, IBDCPA (Figure 2(B)).

From these results, it was found that the thermal curing reaction of each mixture of PNOX/2,2'-BPOX and THPMOX/ 2,2'-BPOX with IBDCPA proceeded smoothly catalyzed by TPPC at higher temperature than $180^{\circ} \mathrm{C}$ in bulk (Scheme 1). 

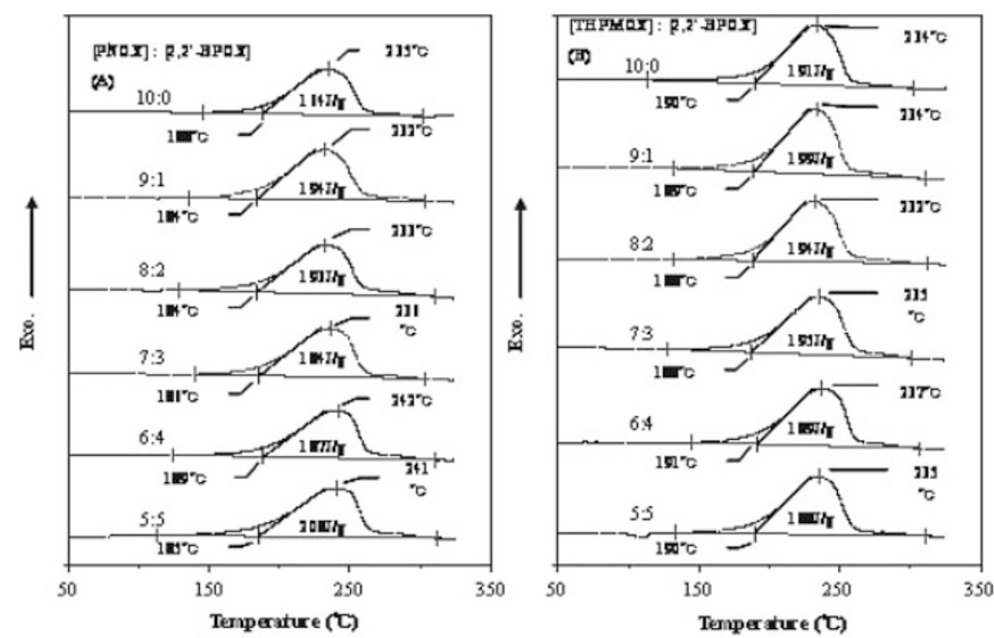

Figure 2. Thermal behavior on the reactions of $P N O X / 2,2^{\prime}-B P O X(A)$ and THPMOX/2,2-BPOX (B).

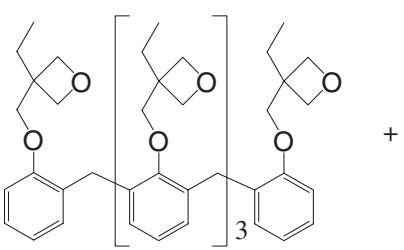

PNOX<smiles>CCC1(COc2ccccc2-c2ccccc2OCC2(CC)COC2)COC1</smiles>

2,2'-BPOX<smiles>CC(=O)Oc1c(Cl)cc(C(C)(C)c2cc(Cl)c(OC(C)=O)c(Cl)c2)cc1Cl</smiles>

IBDCPA

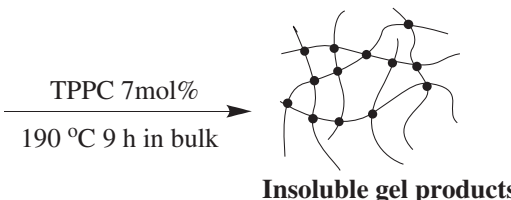

Insoluble gel products

Scheme 1<smiles>CCC1(COc2ccccc2-c2ccccc2OCC2(CC)COC2)COC1</smiles>

2,2'-BPOX<smiles>CC(=O)Oc1c(Cl)cc(C(C)(C)c2cc(Cl)c(OC(C)=O)c(Cl)c2)cc1Cl</smiles>

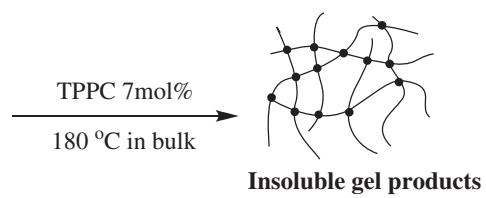

Scheme 2.

Based on the DSC measurement, the thermal-curing reactions of the mixtures of oxetane resins, PNOX/2,2'-BPOX and THPMOX/2,2'-BPOX with IBDCPA were examined using 7 mol-\% of TPPC as a catalyst at $190^{\circ} \mathrm{C}$ for $9 \mathrm{~h}$ and at $180^{\circ} \mathrm{C}$ for $18 \mathrm{~h}$ in bulk, respectively. As summarized in Table II, the reaction of all mixtures of $\mathrm{PNOX} / 2,2^{\prime}$-BPOX with IBDCPA proceeded to give insoluble gel products at $190{ }^{\circ} \mathrm{C}$ for $9 \mathrm{~h}$ in good yields (87-95\%), and it was found that the yields of gel products and $T_{\mathrm{g}} \mathrm{s}\left(97-118^{\circ} \mathrm{C}\right)$ of the cured gel products fell with increasing the feed ratio of $2,2^{\prime}$-BPOX. On the other hand, it seems that the thermal stability based on $T_{\mathrm{d}}{ }^{5 \%}$ and $T_{\mathrm{d}}{ }^{10 \%}$ slightly rose up with increasing the feed ratio of $2,2^{\prime}$-BPOX.

All mixtures of THPMOX $/ 2,2^{\prime}$-BPOX with IBDCPA also produced corresponding gel products at $180^{\circ} \mathrm{C}$ for $18 \mathrm{~h}$ in high yields (85-93\%). In this reaction system, it was also found that the yields of gel products and $T_{\mathrm{g}} \mathrm{S}\left(96-128^{\circ} \mathrm{C}\right)$ of the cured gel 
Table II. Effect of the feed ratio on the reaction of PNOX and 2,2'-BPOX with IBDCPA and thermal property of the cured resin ${ }^{a)}$

\begin{tabular}{ccccc}
\hline Feed ratio (wt \%) & $\begin{array}{c}\text { Yield of gel } \\
\text { products }(\%)^{\mathrm{b})}\end{array}$ & $T_{\mathrm{g}}\left({ }^{\circ} \mathrm{C}\right)^{\mathrm{c})}$ & \multicolumn{2}{c}{$T_{\mathrm{d}}$} \\
\cline { 1 - 2 } PNOX/2,2'-BPOX & & $T_{\mathrm{d}}{ }^{5 \%}\left({ }^{\circ} \mathrm{C}\right)^{\mathrm{d})}$ & $T_{\mathrm{d}}{ }^{10 \%}\left({ }^{\circ} \mathrm{C}\right)^{\mathrm{d})}$ \\
\hline $10: 0$ & 95 & 118 & 375 & 391 \\
$9: 1$ & 94 & 109 & 374 & 391 \\
$8: 2$ & 94 & 105 & 374 & 391 \\
$7: 3$ & 92 & 101 & 378 & 394 \\
$6: 4$ & 87 & 98 & 378 & 394 \\
$5: 5$ & 87 & 97 & 380 & 395 \\
\hline
\end{tabular}

a) The reaction of PNOX and 2,2'-BPOX was carried out with equivenant amount of IBDCPA using $7 \mathrm{~mol} \%$ of TPPC in bulk at $190^{\circ} \mathrm{C}$ for $9 \mathrm{~h}$. b) Insoluble parts in THF. C) Measured by DSC at heating rate of $10^{\circ} \mathrm{C} / \mathrm{min}$ under nitrogen. ${ }^{\text {d) Measured by } T G / D T A}$ at heating rate of $10^{\circ} \mathrm{C} / \mathrm{min}$ under nitrogen.

Table III. Effect of the feed ratio on the reaction of THPMOX and 2,2'-BPOX with IBDCPA and thermal property of the cured resin ${ }^{\mathrm{a})}$

\begin{tabular}{ccccc}
\hline Feed ratio & \multicolumn{2}{c}{$\begin{array}{c}\text { Yield of gel } \\
\text { products }(\%)^{\mathrm{b})}\end{array}$} & $T_{\mathrm{g}}\left({ }^{\circ} \mathrm{C}\right)^{\mathrm{c})}$ & \multicolumn{2}{c}{$T_{\mathrm{d}}$} \\
\cline { 1 - 3 } THPMOX/2,2'-BPOX & & $T_{\mathrm{d}}{ }^{5 \%}\left({ }^{\circ} \mathrm{C}\right)^{\mathrm{d})}$ & $T_{\mathrm{d}}{ }^{10 \%}\left({ }^{\circ} \mathrm{C}\right)^{\mathrm{d})}$ \\
\hline $10: 0$ & 93 & 128 & 381 & 395 \\
$9: 1$ & 93 & 118 & 382 & 396 \\
$8: 2$ & 91 & 111 & 383 & 396 \\
$7: 3$ & 90 & 105 & 382 & 394 \\
$6: 4$ & 86 & 101 & 384 & 398 \\
$5: 5$ & 85 & 96 & 386 & 398 \\
\hline
\end{tabular}

a) The reaction was carried out with THPMOX, 2,2'-BPOX and IBDCPA as a curing agent using $7 \mathrm{~mol} \%$ of TPPC in bulk at $180^{\circ} \mathrm{C}$ for $18 \mathrm{~h}$. b) Insoluble parts in THF. C) Measured by DSC at heating rate of $10^{\circ} \mathrm{C} / \mathrm{min}$ under $\mathrm{N}_{2}$. ${ }^{\text {d) }}$ Measured by TG/DTA at heating rate of $10^{\circ} \mathrm{C} / \mathrm{min}$ under $\mathrm{N}_{2}$.

products fell with increasing the feed ratio of $2,2^{\prime}$-BPOX (Table III). These results showed that the yields of cross-linked products, $T_{\mathrm{g}} \mathrm{s}$ of the cured resins, and the cross-link densities of the cured oxetane resins decreased gradually with increasing di-functional oxetane compound, 2,2'-BPOX.

However, the thermal stability of the cured resins of THPMOX and 2,2'-BPOX with IBDCPA slightly increased with increasing the feed ratio of $2,2^{\prime}$-BPOX from the TGA data $\left(T_{\mathrm{d}}{ }^{5 \%}\right.$ and $\left.T_{\mathrm{d}}{ }^{10 \%}\right)$ as same as the cured resin from PNOX and $2,2^{\prime}$-BPOX with IBDCPA. It seems that thermally stable biphenyl structure of 2,2'-BPOX caused high thermal stability of the cured resins.

IR spectrum of the cured resin from $\operatorname{PNOX}(8) / 2,2^{\prime}$ BPOX(2) with IBDCPA showed new appearance of the absorption band at $1742 \mathrm{~cm}^{-1}$ due to the $\mathrm{C}=\mathrm{O}$ stretching from alkyl ester linkage, and disappearance of the absorption bands at $1775 \mathrm{~cm}^{-1}$ due to the $\mathrm{C}=\mathrm{O}$ stretching from aryl ester linkage and at $980 \mathrm{~cm}^{-1}$ due to cyclic oxetane ring. IR spectrum of the cured resin from THPMOX(8)/2,2'-BPOX(2) with IBDCPA also showed new appearance of the absorption band at $1743 \mathrm{~cm}^{-1}$ due to the $\mathrm{C}=\mathrm{O}$ stretching from alkyl ester linkage, and disappearance of the absorption bands at $1774 \mathrm{~cm}^{-1}$ due to the $\mathrm{C}=\mathrm{O}$ stretching from aryl ester linkage and at $976 \mathrm{~cm}^{-1}$ due to cyclic oxetane ring. These IR spectra data suggest that the ring-opening addition reaction of oxetane groups with active ester proceeded in bulk as same as in the solution conditions.
Table IV. Effect of catalysts on the thermal curing reaction of PNOX and $2,2^{\prime}-B P O X$ with IBDCPA and thermal property of the cured resins ${ }^{\text {a) }}$

\begin{tabular}{ccccc}
\hline \multirow{2}{*}{ Catalyst } & $\begin{array}{c}\text { Yield of gel } \\
\text { products }(\%)^{\mathrm{b})}\end{array}$ & \multirow{2}{*}{$T_{\mathrm{g}}\left({ }^{\circ} \mathrm{C}\right)^{\mathrm{c})}$} & \multicolumn{2}{c}{$T_{\mathrm{d}}$} \\
\cline { 4 - 5 } & & 112 & $T_{\mathrm{d}}{ }^{5 \%}\left({ }^{\circ} \mathrm{C}\right)^{\mathrm{d})}$ & $T_{\mathrm{d}}{ }^{10 \%}\left({ }^{\circ} \mathrm{C}\right)^{\mathrm{d})}$ \\
\hline TPPI & 54 & 112 & 344 & 374 \\
TPPB & 86 & 108 & 376 & 391 \\
TPPC & 92 & 106 & 380 & 395 \\
\hline
\end{tabular}

a) The reaction was carried out with PNOX $(0.4 \mathrm{~g}), 2,2^{\prime}-\operatorname{BPOX}(0.1 \mathrm{~g})$ and IBDCPA $(0.564 \mathrm{~g}) 10 \mathrm{~mol} \%$ of catalyst in bulk at $180^{\circ} \mathrm{C}$ for $18 \mathrm{~h}$. ${ }^{\text {b) Insoluble }}$ parts in THF. C) Measured by DSC at heating rate of $10^{\circ} \mathrm{C} / \mathrm{min}$ under nitrogen. ${ }^{\text {d) }}$ Measured by TG/DTA at heating rate of $10^{\circ} \mathrm{C} / \mathrm{min}$ under nitrogen.

Based on the above results, the effect of catalysts was examined on the reaction of the mixture of $\operatorname{PNOX}(8) / 2,2^{\prime}-$ $\operatorname{BPOX}(2)$ with equivalent amount of IBDCPA at $180^{\circ} \mathrm{C} 18 \mathrm{~h}$ using $10 \mathrm{~mol} \%$ of catalysts, and it was found that when TPPI, TPPB, and TPPC were used as catalysts, yields of gel products were 54, 86, and 92\%, respectively (Table IV). This means that TPPC had suitable catalytic activity than TPPI and TPPB under this reaction condition from view point of gel production. On the other hand, interestingly the obtained gel products from the reaction using TPPI showed slightly higher $T_{\mathrm{g}}$ than gel products catalyzed by TPPC and TPPB; however, we do not have appropriate reason to explain about this phenomenon.

The thermal-curing reaction of $\operatorname{PNOX}(8) / 2,2^{\prime}-\mathrm{BPOX}(2)$ with equivalent IBDCPA was performed at $180^{\circ} \mathrm{C}$ using 5 and $7 \mathrm{~mol} \%$ of TPPC as a catalyst in bulk. As shown in Figure 3 , the yields of gel products were $0,74,77,78,81$, and $84 \%$ at $3,6,9,12,18$, and $24 \mathrm{~h}$, respectively, when the reaction was carried out with $5 \mathrm{~mol} \%$ of TPPC. That is, there is induction period at until $3 \mathrm{~h}$ in this reaction condition. On the other hand, when the reaction was took place with $7 \mathrm{mo} \%$ of TPPC, there is no induction period and the yields of insoluble gel products were $57,83,84,84,93$, and $95 \%$ at $3,6,9,12,18$, and $24 \mathrm{~h}$, respectively.

The thermal curing reaction of $\operatorname{PNOX}(8) / 2,2^{\prime}-\operatorname{BPOX}(2)$ with equivalent IBDCPA was examined at 170, 180, and

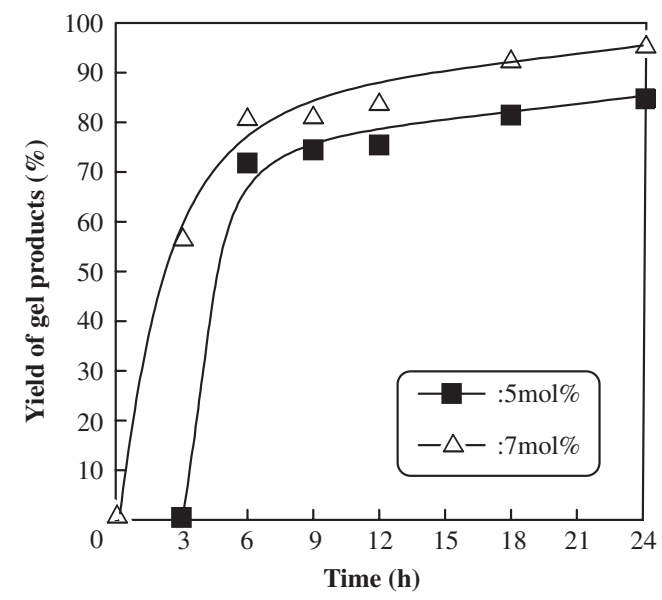

Figure 3. Effect of catalyst concentration on the thermal curing reaction of PNOX and 2,2'-BPOX with IBDCPA using TPPC as the catalyst at $180^{\circ} \mathrm{C}$ in bulk; weight ratio of $\mathrm{PNOX} / 2,2^{\prime}-\mathrm{BPOX}=8 / 2$. 


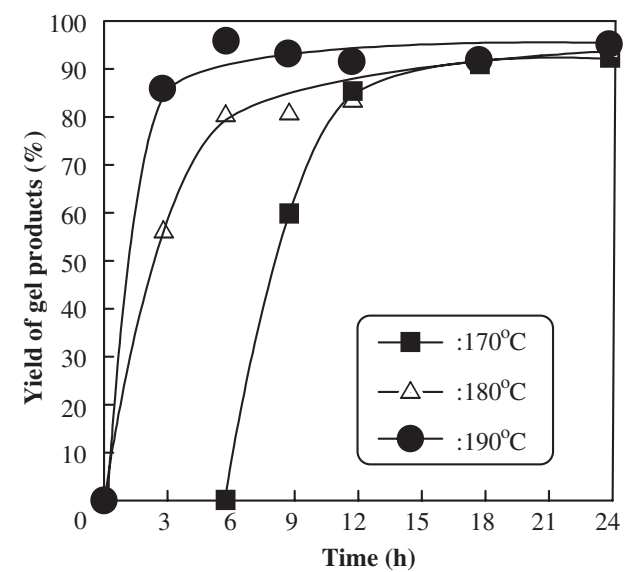

Figure 4. Effect of the temperature on the reaction of PNOX and 2,2'-BPOX with IBDCPA using $7 \mathrm{mo}-\%$ of TPPC as the catalyst; weight ratio of PNOX $/ 2,2^{\prime}-\mathrm{BPOX}=8 / 2$.

Table V. Effect of the feed ratio of IBDCPA on the reaction with PNOX and $2,2^{\prime}-\mathrm{BPOX}$ and thermal property of the cured resin ${ }^{\mathrm{a}}$ )

\begin{tabular}{rcrcc}
\hline \multirow{2}{*}{ IBDCPA } & $\begin{array}{c}\text { Yield of gel } \\
\text { products }(\%)^{\mathrm{b})}\end{array}$ & $T_{\mathrm{g}}\left({ }^{\circ} \mathrm{C}\right)^{\mathrm{b})}$ & \multicolumn{2}{c}{$T_{\mathrm{d}}$} \\
\cline { 4 - 5 } & 88 & 99 & 324 & 336 \\
\hline $70 \%$ & 94 & 105 & 374 & 391 \\
$100 \%$ & 79 & 97 & 359 & 381 \\
$130 \%$ & 53 & 97 & 356 & 377 \\
$150 \%$ & & $97 \mathrm{C})^{\mathrm{c})}$ & $T_{\mathrm{d}}{ }^{10 \%}\left({ }^{\circ} \mathrm{C}\right)^{\mathrm{c})}$ \\
\hline
\end{tabular}

a) The reaction was carried out with PNOX $(0.4 \mathrm{~g}), 2,2^{\prime}-\operatorname{BPOX}(0.1 \mathrm{~g})$ and IBDCPA as a curing agent using $7 \mathrm{~mol} \%$ of TPPC in bulk at $180^{\circ} \mathrm{C}$ for $18 \mathrm{~h}$. b) Insoluble parts in THF. C) Measured by DSC at heating rate of $10^{\circ} \mathrm{C} / \mathrm{min}$ under nitrogen. ${ }^{\text {d) }}$ Measured by TG/DTA at heating rate of $10^{\circ} \mathrm{C} / \mathrm{min}$ under nitrogen.

$190{ }^{\circ} \mathrm{C}$ using $7 \mathrm{~mol} \%$ of TPPC as a catalyst in bulk. As shown in Figure 4, the yields of insoluble gel production increased with reaction time, and the yields of gel products at $6 \mathrm{~h}$ were 95,83 , and $0 \%$ at 190,180 , and $170^{\circ} \mathrm{C}$, respectively. This means that the thermal curing reaction of oxetane resins with active ester IBDCPA proceed smoothly at higher temperature than $180^{\circ} \mathrm{C}$ in bulk.

The thermal curing reaction of $\operatorname{PNOX}(8) / 2,2^{\prime}-\operatorname{BPOX}(2)$ and IBDCPA under different molar ratio was examined at $180^{\circ} \mathrm{C}$ for $18 \mathrm{~h}$ using $7 \mathrm{~mol} \%$ of TPPC as a catalyst. When the reactions were performed with oxetane resin(1.0)/IBDCPA(0.7), oxetane resin(1.0)/IBDCPA(1.0), oxetane resin(1.0)/IBDCPA(1.3), and oxetane resin(1.0)/IBDCPA(1.5), yields of insoluble gel products were $88,94,79$, and $53 \%$, and $T_{\mathrm{g}} \mathrm{s}$ of the resulting gel products were $99,105,97$, and $97^{\circ} \mathrm{C}$, respectively (Table V). These results mean that equivalent reaction of oxetane resin and active ester produced gel products with the highest $T_{\mathrm{g}}$ in the highest yield. It was also found that the gel products obtained on the equivalent reaction of oxetane resin with crosslinker showed the higher thermal stability than other gel products prepared from non-equivalent reaction of oxetane with cross-linker. This means that the equivalent feed ratio is an important factor to obtain good cured products on the thermal curing reaction of oxetane resin with di-functional active ester, IBDCPA. This result also suggests that the cured resin from equivalent reaction of oxetane resin and active ester, which has the highest cross-link, has the high $T_{\mathrm{g}}$ and good thermal stability.

\section{CONCLUSION}

From all results, following conclusions can be drawn: 1) The thermal curing reaction of oxetane resins (PNOX/2,2'-BPOX and THPMOX $\left./ 2,2^{\prime}-\mathrm{BPOX}\right)$ with polyfunctional active ester (IBDCPA) proceeded successfully at $170-190^{\circ} \mathrm{C}$ using appropriate quaternary phosphonium salts as catalysts to give the corresponding insoluble gel products. 2) The cured oxetane resins had good thermal properties such as $T_{\mathrm{g}}=96-128^{\circ} \mathrm{C}$ and $T_{\mathrm{d}}{ }^{5 \%}=374-386^{\circ} \mathrm{C}$, when the reaction proceeded in high conversions. 3) Thermal curing system of oxetane resin with active ester has great possibilities as a novel thermo-setting resin.

Acknowledgment. Thermal analysis of the mixture of oxetane resins with cross-linker IBDCPA and without IBDCPA was performed by reverse heat flow method using a TA Instruments model DSC Q100 differential scanning calorimeter (DSC), which was kindly operated by Mr. Shigeru Matsumoto and Mr. Yoshitaka Hirai, Research Institute, Taiyo Ink Mfg. Co., Ltd. The authors would like to express our acknowledgment for their great contribution to this research.

Received: October 12, 2007 Accepted: December 19, 2007 Published: March 4, 2008

\section{REFERENCES}

1. a) Y. Iwakura and K. Kurita, "Reactive Polymers," Kodansha, Tokyo, 1977.

b) "Epoxy Resin," H. Kakiuchi, Ed., Shokodo, Tokyo, 1985.

2. a) T. Nishikubo, J. Synth, Org. Chem. Jpn., 49, 218 (1991).

b) T. Nishikubo and A. Kameyama, Prog. Polym. Sci., 18, 963 (1993).

3. T. Nishikubo and K. Tanaka, J. Appl. Polym. Sci., 33, 2821 (1987).

4. A. S. Pell and G. Pilchere, Trans Faraday Soc., 61, 71 (1965).

5. a) T. Saegusa, Y. Hashimoto, and S. Matsumoto, Macromolecules, 4, 1 (1971).

b) T. Saegusa, H. Fujii, S. Kobayashi, H. Ando, and R. Kawase, Macromolecules, 6, 26 (1973).

c) M. Motoi, H. Suda, K. Shimamura, S. Nagahara, S. Takei, and S. Kanoh, Bull. Chem. Soc. Jpn., 61, 1653 (1988).

d) S. Inoue and T. Aida, "Ring-Opening Polymerization," Vol. 1, K. J. Ivin and S. Saegusa, Ed., Elsevier, London, pp. 185-298, 1984.

6. a) S. Kanoh, T. Nishimura, Y. Kita, H. Ogawa, M. Motoi, M. Takani, and T. Tanaka, J. Org. Chem., 65, 2253 (2000).

b) S. Kanoh, T. Nishimura, H. Senda, H. Ogawa, and M. Motoi, Macromolecules, 32, 2438 (1999).

c) S. Kanoh, T. Nishimura, K. Hada, H. Senda, H. Ogawa, and M. Motoi, Macromolecules, 31, 7988 (1998).

7. a) T. Nishikubo and K. Sato, Chem. Lett., 697 (1991).

b) A. Kameyama, Y. Yamamoto, and T. Nishikubo, J. Polym. Sci., Part A: Polym. Chem., 31, 1639 (1993).

c) A. Kameyama, Y. Yamamoto, and T. Nishikubo, Macromol. Chem. Phys., 197, 1147 (1996).

d) T. Yashiro, T. Saito, A. Kameyama, and T. Nishikubo, J. Polym. 
Sci., Part A: Polym. Chem., 41, 2304 (2003).

8. S. Minegishi, M. Ito, A. Kameyama, and T. Nishikubo, J. Polym. Sci., Part A: Polym. Chem., 38, 2254 (2000).

9. S. Minegishi, S. Tsuchida, M. Sasaki, A. Kameyama, and T. Nishikubo, J. Polym. Sci., Part A: Polym. Chem., 40, 3835 (2002).

10. a) T. Nishikubo, A. Kameyama, M. Ito, T. Nakajima, and H. Miyazaki, J. Polym. Sci., Part A: Polym. Chem., 37, 2781 (1999).

b) Y. Konno, H. Suzuki, H. Kudo, A. Kameyama, and T. Nishikubo, Polym. J., 2004, 36, 114 (2004).

11. T. Nishikubo, A. Kameyama, M. Ito, and A. Suzuki, J. Polym. Sci., Part A: Polym. Chem., 36, 2873 (1998).

12. T. Nishikubo, A. Kameyama, and A. Suzuki, React. Funct. Polym.,
37, 19 (1998).

13. H. Kudo, T. Kurakata, M. Sasaki, and T. Nishikubo, J. Polym. Sci., Part A: Polym. Chem., 42, 1528 (2004).

14. a) H. Kudo, A. Morita, and T. Nishikubo, Polym. J., 35, 88 (2003). b) A. Morita, H. Kudo, and T. Nishikubo, Polym. J., 36, 413 (2004). c) A. Morita, H. Kudo, and T. Nishikubo, J. Polym. Sci., Part A: Polym. Chem., 42, 3739 (2004).

15. A. Kameyama, K. Ueda, H. Kudo, and T. Nishikubo, Macromolecules, 35, 3792 (2002).

16. T. Nishikubo, H. Kudo, M. Sasaki, K. Kuwamura, and C. Imataki, Polym. J., 36, 841 (2004). 